\title{
Potential role of HER-2 in primary breast tumor with bone metastasis
}

\author{
RYUNGSA KIM ${ }^{1}$, KOJI ARIHIRO ${ }^{2}$, MANABU EMI $^{3}$, KAZUAKI TANABE $^{3}$ and AKIHIKO OSAKI ${ }^{3}$ \\ ${ }^{1}$ International Radiation Information Center, ${ }^{2}$ Department of Pathology, Hiroshima University Hospital, ${ }^{3}$ Department of \\ Surgical Oncology, Research Institute for Radiation Biology and Medicine, Hiroshima University, Hiroshima, Japan
}

Received January 10, 2006; Accepted February 27, 2006

\begin{abstract}
HER-2 is an important prognostic factor in breast cancer, and its overexpression is observed in $20-60 \%$ of cases with micrometastases in the bone marrow. The aim of this study was to explore the potential functional role of HER-2 in primary breast tumors with bone metastases. Forty-eight primary breast tumors with simultaneous or non-simultaneous bone metastases were studied. The expression of hormone receptors, and metastasis and growth factor-related proteins were assessed by immunohistochemical staining. The correlation in statistical significance was assessed by the Chisquare test. Of the 48 breast tumors, 11 (22.9\%) were HER-2positive and 37 were HER-2-negative. There was no significant difference in HER-2 status and clinicopathologic factors between the two groups. Of the 11 HER-2-positive tumors, there were 2 and 3 cases that showed positive nuclear expression for estrogen and progesterone receptors, respectively. No extranuclear expression of HRs was detected in these tumors. For metastasis-related proteins such as c-Met, VEGF, and MTA-1, which are activated by HER-2, only some insignificant focal expression of these proteins was observed. An increased level of pAkt was observed in 9 (81.8\%) of 11 tumors, and an increased expression of CXCR4 was observed in $6(54.5 \%)$ of 11 tumors. The frequency of increased levels of pAkt and CXCR4 was not significant between HER-2positive and -negative tumors. The increased levels of pAkt and CXCR 4 are induced by factors that are both dependent and independent of HER-2, and the activation of HER-2/CXCR4/ Akt signaling pathway in primary breast tumors may contribute to the formation of bone metastases in breast cancer.
\end{abstract}

\section{Introduction}

HER-2 is a member of the epidermal growth factor family, which plays an important role in tumor progression and metastasis (1). The overexpression of HER-2 is observed in

Correspondence to: Dr Ryungsa Kim, International Radiation Information Center, Research Institute for Radiation Biology and Medicine, Hiroshima University, 1-2-3 Kasumi Minami-ku, Hiroshima 734-8553, Japan

E-mail: rkim@hiroshima-u.ac.jp

Key words: HER-2, Akt, CXCR4, breast cancer, bone metastasis
$20-30 \%$ of primary breast cancers (2), and is associated with poor prognosis and less responsiveness to endocrine chemotherapy compared to HER-2-negative tumors $(3,4)$. Despite the fact that bone metastasis is the most frequent distant metastasis noted in breast cancer, the overexpression of HER-2 is observed in $20-60 \%$ of the micrometastases in bone marrow $(5,6)$. These findings suggest that the overexpression of HER-2 in primary breast tumors may play a critical role in the formation of bone metastases in which the breast cancer cells overexpressing HER-2 can be selected for the specific clones predisposed by certain genetic changes for bone metastasis.

The overexpression of HER-2 is cross-linked with other growth factor-signaling pathways such as IGF-IR (7), which activates the c-Met signaling pathway (8) that is, in turn, connected with the activation of VEGF (9). In addition, HER-2 induces metastasis-associated protein 1 (MTA-1), which interacts with the AF-2 domain of estrogen receptors (ERs), resulting in the extranuclear expression of ER by cytoplasmic translocation (10). Thus, there are several signal transduction pathways involved with HER-2 and other growth factors that may produce the malignant phenotype for bone metastasis.

The other important factor for establishing metastasis in cancer cells is the interaction of chemokine and the chemokine receptor between the primary and metastatic site $(11,12)$. Previous reports indicate that the expression of the chemokine receptor, CXCR4, at a primary tumor site plays a critical role in recruiting tumor cells to the metastatic site, which secretes the chemokine, CXCL12 (SDF-1) $(11,12)$. In the case of bone marrow, given that a high expression of CXCL12 was observed, the expression of CXCR4 in the primary tumor may be involved in bone metastasis in breast cancer. HER-2 enhanced the expression of CXCR4 in cancer cells, and a significant correlation between HER-2 and CXCR4 expression was observed in human breast tumor tissue (13). Furthermore, HER-2 stabilizes CXCR4 protein, which is linked to poor prognosis in breast cancer cells (14). Based on these findings, we studied the expression of several metastasis-related proteins that were triggered by the overexpression of HER-2, and whether there is any predictive marker in primary breast tumors leading to bone metastases.

\section{Patients and methods}

Patients. The subjects of this study consisted of 48 primary breast tumors with bone metastasis, including 16 simultaneous and 32 non-simultaneous metastases. The patients were treated at the Department of Surgical Oncology, Research 
Institute for Radiation Biology and Medicine, Hiroshima University (Hiroshima, Japan) between 1980 and 2001. The clinical stages and pathological characteristics were described according to the general rules for the clinical and pathological recording of breast cancer established by the Japanese Breast Cancer Society (15).

Immunohistochemical staining and assessment. Immunohistochemical staining for the estrogen receptor (ER), progesterone receptor (PR), and HER-2 was performed according to previously reported methods $(16,17)$. All specimens were fixed in $10 \%$ formalin, routinely processed, and embedded in paraffin. Tissues were deparaffinized in xylene and rehydrated through $100 \%, 95 \%$ and $90 \%$ ethanol. To overcome crosslinking due to formalin fixation, heat treatment with the epitope retrieval solution composed of $50 \mathrm{mmol} / \mathrm{l}$ Tris- $\mathrm{HCl}$ buffer ( $\mathrm{pH} 10.0$ ) was performed in a water bath at $95^{\circ} \mathrm{C}$ for $40 \mathrm{~min}$ followed by a $20 \mathrm{~min}$ cool-down period at room temperature (RT). The tissue sections were immunostained for ER and PR using an automated staining system (Dako Autostainer; DakoCytomation A/S, Glostrup, Denmark). In brief, all sections were reacted with $0.3 \%$ hydrogen peroxide solution containing $15 \mathrm{mmol} / \mathrm{l}$ sodium azide for $10 \mathrm{~min}$ at room temperature (RT) to block endogenous peroxidase activity, then thoroughly rinsed in washing buffer $(50 \mathrm{mmol} / \mathrm{l}$ Tris- $\mathrm{HCl}$ buffered saline containing a detergent, $\mathrm{pH}$ 7.6). The sections were incubated with anti-ER and anti-PR mAbs (clones 1D5 and PR636, respectively; DakoCytomation A/S) at RT for $30 \mathrm{~min}$, then washed three times with the washing buffer. Bound antibodies were detected by 30 -min incubation with dextran polymer reagent conjugated with peroxidase and secondary antibody (Dako EnVision+; DakoCytomation $\mathrm{A} / \mathrm{S}$ ). The tissues were then washed three times with washing buffer. Color development was achieved with 3,3'-diaminobenzidine (Dako DAB+ Liquid System; DakoCytomation $\mathrm{A} / \mathrm{S}$ ) for $10 \mathrm{~min}$. The tissues were counterstained with hematoxylin at RT for $2 \mathrm{~min}$. If $>10 \%$ of tumor cells showed nuclear staining for ER or PR, the specimen was considered positive for that receptor. The staining intensity of ER and PR was graded in four categories: 0, negative; $1+$, weak; $2+$, moderate; and 3+, strong.

For the assessment of HER-2, the Hercep Test ${ }^{\mathrm{TM}}$ (Dako, Kyoto, Japan) was used according to protocol described in the manufacturer's guide. Briefly, after deparaffinizing with xylene and ethanol, the sections were incubated in a water bath for $40 \mathrm{~min}$ at $95^{\circ} \mathrm{C}$ in a $10 \mathrm{mmol} / 1$ citrate buffer ( $\mathrm{pH}$ 6.0). The slides were incubated with the prediluted primary rabbit polyclonal antibody supplied in the kit for $30 \mathrm{~min}$. The immunoreaction was visualized by incubating slides with the Dako visualization reagent (Dako A/S) (dextran polymer conjugated with horseradish peroxidase and goat-antirabbit immunoglobulin) for $30 \mathrm{~min}$ at RT. 3,3'-diaminobenzidine tetrahydrochloride was used as the chromogen. Negative controls consisted of substituting normal rabbit serum for the primary antibody. Assessment of the Hercep test was performed according to the following criteria: 0 , no staining, or membrane staining in $<10 \%$ of the tumor cells; $1+$, faint/barely perceptible membrane staining in $>10 \%$ of tumor cells; $2+$ and $3+$, weak to moderate staining or strong staining of the entire membrane in $>10 \%$ of the tumor cells.
Table I. Patient characteristics.

\begin{tabular}{lccr}
\hline & \multicolumn{2}{c}{ HER-2 (\%) } & \\
\cline { 2 - 3 } $\begin{array}{l}\text { Clinicopathological } \\
\text { factor }\end{array}$ & $\begin{array}{c}\text { Positive } \\
(\mathrm{n}=11)\end{array}$ & $\begin{array}{c}\text { Negative } \\
(\mathrm{n}=37)\end{array}$ & p-value \\
\hline $\begin{array}{l}\text { Age (years) } \\
\quad \text { Median (range) }\end{array}$ & $47(25-65)$ & $57(23-79)$ & \\
Clinical stage & & & \\
I & $2(18.1)$ & $1(2.7)$ & \\
II & $3(27.2)$ & $16(43.2)$ & 0.24 \\
III & $2(18.1)$ & $10(27.0)$ & \\
IV & $4(36.3)$ & $12(32.4)$ &
\end{tabular}

Clinical lymph

node status

$\begin{array}{lcc}\text { N0 } & 6(54.5) & 9(24.3) \\ \text { N1 } & 3(27.2) & 17(45.9) \\ \text { N2 } & 1(9.0) & 6(16.2) \\ \text { N3 } & 1(9.0) & 1(2.7) \\ \text { Unknown } & 0 & 4(10.8)\end{array}$

$\begin{array}{lcc}\begin{array}{l}\text { Histology } \\ \text { Ductal }\end{array} & & \\ \text { Pap-tub } & 0 & 3(8.1) \\ \text { Sol-tub } & 3(27.2) & 12(32.4) \\ \text { Sci } & 8(72.7) & 18(48.6) \\ \text { Others } & 0 & 4(10.8)\end{array}$

ER

$\begin{array}{lcc}\text { Positive } & 6(54.5) & 19(51.3) \\ \text { Negative } & 5(45.4) & 16(43.2) \\ \text { Unknown } & 0 & 2(5.4)\end{array}$

PR

$\begin{array}{lcc}\text { Positive } & 4(36.3) & 19(51.3) \\ \text { Negative } & 5(45.4) & 12(32.4) \\ \text { Unknown } & 2(18.1) & 0\end{array}$

Menopause

$\begin{array}{llll}\text { Pre } & 5(45.4) & 18(48.6) & 0.85 \\ \text { Post } & 6(54.5) & 19(51.3) & \end{array}$

N, node; Pap-tub, papillotubular; Sci, scirrhous; Sol-tub, solid-

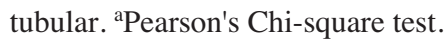

Only $2+$ and $3+$ scores were assessed as the overexpression of HER-2.

For the assessment of c-Met, VEGF, MTA-1, Akt, and pAkt expression, the tissues were deparaffinized and then immunohistochemically stained according to the manufacturers' protocols (Santa Cruz Biotechnology, Inc., CA; Abcam, Cambridge, UK). The slides were incubated with primary antibody for c-Met (Met, rabbit polyclonal IgG; Santa Cruz), VEGF (VEGF, mouse monoclonal IgG2a; Santa Cruz), MTA-1 (MTA1, mouse monoclonal IgG; Santa Cruz), Akt (Akt1/2, 
A

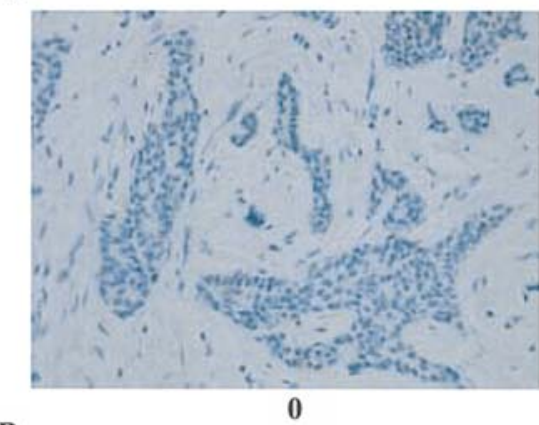

B

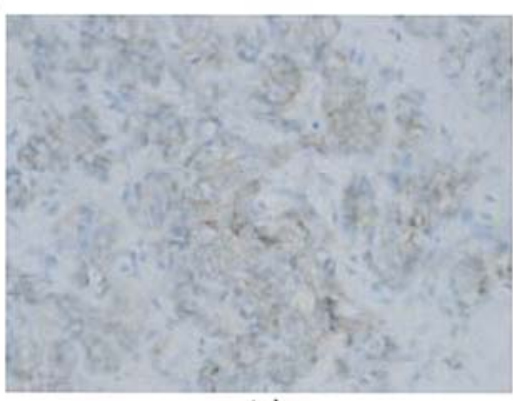

C

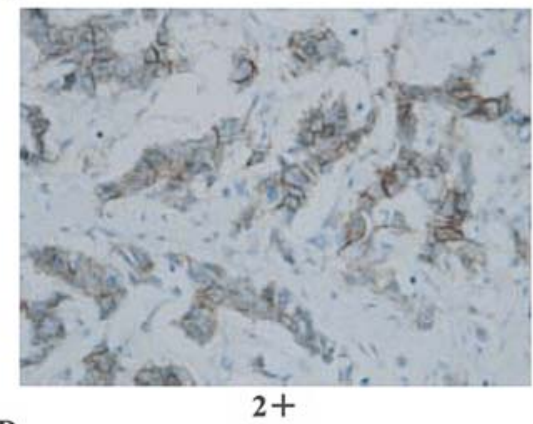

D

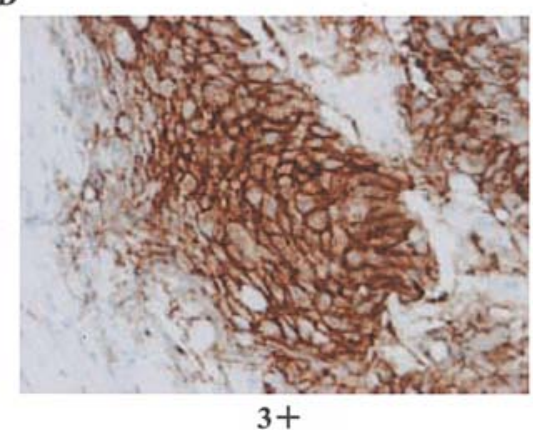

Figure 1. Typical expression levels of HER-2 assessed in primary breast tumors. (A) 0 , no staining, or membrane staining in $<10 \%$ of the tumor cells; (B) $1+$, faint/barely perceptible membrane staining in $>10 \%$ of the tumor cells; (C and D) $2+$ and $3+$, weak to moderate staining or strong staining of the entire membrane in $>10 \%$ of the tumor cells (original magnification, $\mathrm{x} 200$ ).

A

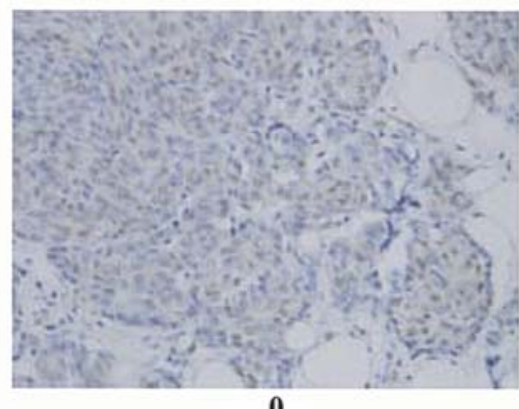

B

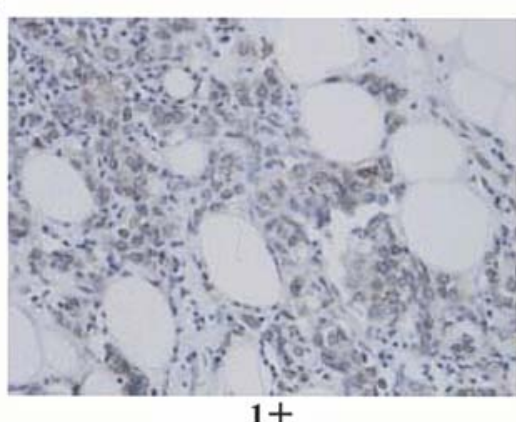

C

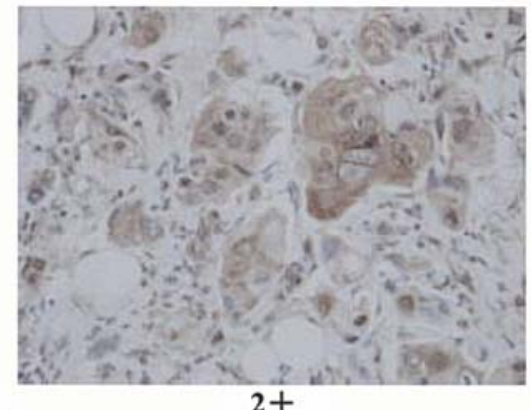

D

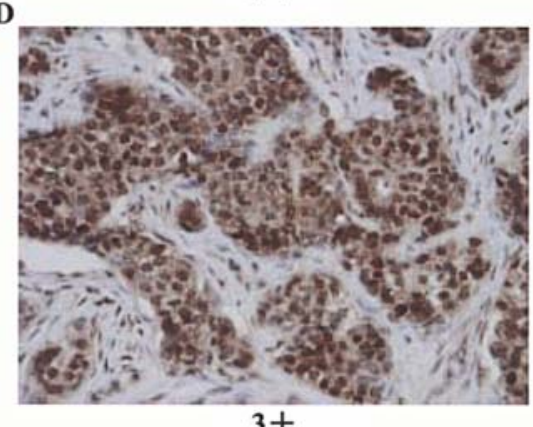

Figure 2. Typical expression levels of pAkt assessed in primary breast tumors. (A) 0 , negative; (B) $1+$, weak; (C) 2+, moderate; and (D) 3+, strong staining (original magnification, $\mathrm{x} 200$ ).

goat polyclonal IgG; Santa Cruz), and pAkt [p-Akt1/2/3 (Thr 308), rabbit polyclonal; Santa Cruz]. In the case of CXCR4, the primary antibody (CXCR4, rabbit polyclonal IgG; Abcam) was used. Slides were incubated with the dextran polymer reagent conjugated with peroxidase and secondary antibody, and color development was achieved with 3,3'-diaminobenzidine. The staining was graded as: 0 , negative; $1+$, weak; $2+$, moderate; and $3+$, strong.

Levels of ER and PR by ELISA. Some of the breast cancer tissues were also subjected to ELISA (enzyme-linked immunosorbent assay; SRL, Tokyo, Japan) to measure the levels of 


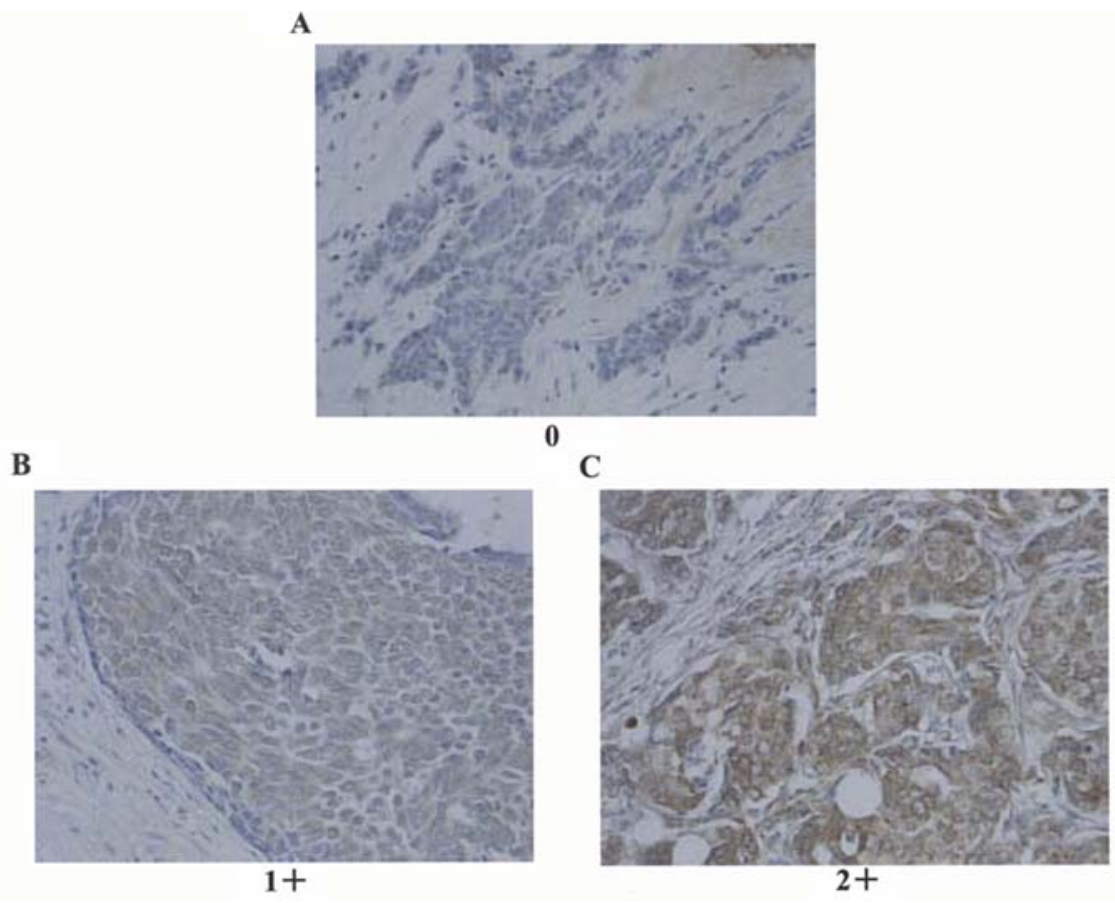

Figure 3. Typical expression levels of CXCR4 assessed in primary breast tumors. (A) 0 , negative; (B) $1+$, weak; and (C) 2+, moderate staining (original magnification, x200).

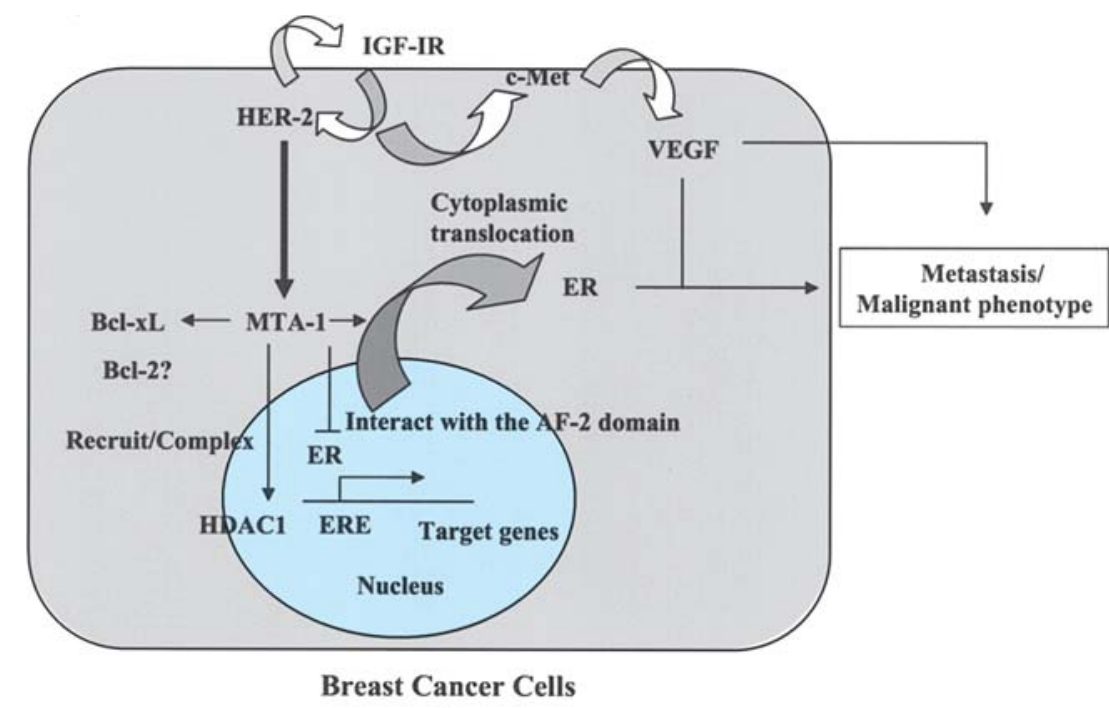

Figure 4. The interaction between HER-2 and metastasis-related proteins such as IGF-RI, c-Met, metastasis-associated protein 1 (MTA-1), and VEGF in tumor progression and metastasis in breast cancer cells. HER-2 is able to form heterodimers with IGF-RI, activate c-Met, and induce the expression of VEGF via HIF-1 in the tumor microenvironment for angiogenesis. MTA-1 recruits and complexes with HDAC1, thereby inhibiting the estrogen receptor (ER)dependent transcription for target genes through an estrogen-responsive element, which produces cytoplasmic translocation of ER in the cross-link with other growth factors. MTA-1 also induces Bcl-xL, which is involved in tumor cell survival and proliferation.

ER and PR, which were compared to results obtained by immunohistochemical analysis.

Statistical analysis. Statistical assessment was performed with the Chi-square test. A p-value $<0.05$ was considered significant.

\section{Results}

Overexpression of HER-2 in primary breast cancers with bone metastasis. Since micrometastasis in bone marrow was observed in $20-30 \%$ of breast cancers, a high frequency of HER-2 overexpression was expected in metastatic breast tumors. Unexpectedly, the frequency of HER-2 overexpression was observed in $11(22.9 \%)$ of 48 breast tumors with bone metastases that included 16 simultaneous and 32 nonsimultaneous metastases. This was similar to the general frequency of HER-2 overexpression in breast cancer. In addition, there was no significant difference in clinicopathological factors between HER-2-positive and HER-2-negative tumors (Table I). Typical expression levels for the assessment of HER-2 are presented in Fig. 1. 
Table II. Expression of hormone receptors in HER-2overexpressing breast cancer in patients with bone metastasis.

\begin{tabular}{clllll}
\hline \multirow{2}{*}{$\begin{array}{c}\text { Patient } \\
\text { no. }\end{array}$} & ER & & \multicolumn{2}{c}{ ELISA } \\
\cline { 2 - 3 } \cline { 5 - 6 } & & PR & PR \\
\hline 1 & $1+$ focal $(1 \%)$ & $2+(50 \%)$ & & - & ND \\
2 & - & $2+$ focal $(2 \%)$ & & + & + \\
3 & $2+$ focal $(1 \%)$ & $2+$ focal $(1 \%)$ & & + & - \\
4 & $+(10 \%)$ & - & & - & ND \\
5 & $2+$ focal $(5 \%)$ & $3+(20 \%)$ & & + & + \\
6 & - & - & - & - \\
7 & $3+(60 \%)$ & $3+(20 \%)$ & & + & + \\
8 & - & - & - & - \\
9 & $3+(5 \%)$ & $3+(1 \%)$ & + & + \\
10 & $2+(5 \%)$ & - & + & - \\
11 & - & - & - & - \\
\hline
\end{tabular}

ER, estrogen receptor; PR, progesterone receptor; IHC, immunohistochemical staining; ELISA, enzyme-linked immunosorbent assay; ND, not done.

Expression of hormone receptors in HER-2-overexpressing breast cancer. To explore the characteristics of patients in which HER-2 overexpression was detected in metastatic breast tumors, the expression of hormone receptors (HRs) such as ER and PR was assessed by immunohistochemical staining (IHC) and ELISA. Although some focal expression of ER and PR was observed among the 11 tumors, the positive expression of ER and PR was observed only in $2(18.1 \%)$ and $3(27.2 \%)$ cases, respectively (Table II). Although the reason for the positive results of ELISA not being detected by $\mathrm{IHC}$ is unclear, it is likely that the assessment of HR expression is more sensitive in ELISA. The low frequency in the positive expression of HRs in these HER-2-overexpressing breast tumors is consistent with a previous report (18). It is noteworthy that any extranuclear expression of HRs was not detected in these tumors, suggesting that the extranuclear expression of HRs triggered by HER-2 is rare in breast cancer with bone metastasis.

Expression of metastasis-related proteins in breast cancer with bone metastasis. It is known that several metastasisrelated proteins, such as c-Met, VEGF, MTA-1, Akt, and CXCR4, are induced by the overexpression of HER-2. Therefore, to explore the metastatic phenotype in bone metastasis triggered by HER-2, the expression of these proteins was assessed in each of the 11 breast tumors in which HER-2 was overexpressed. Although some focal expression of c-Met, VEGF, and MTA-1 was observed, significant positive expression was not. Similarly, Akt expression was not observed in these tumors. In contrast, the level of pAkt was increased in $9(81.8 \%)$ of 11 tumors. Furthermore, the increased expression of CXCR 4 was observed in the cytoplasm in $6(54.5 \%)$ of 11 tumors (Table III). Typical increased levels of pAkt and CXCR4 are presented in Figs. 2 and 3. To assess whether the increased levels of pAkt and CXCR4 were specific for HER-2-positive breast tumors with bone metastasis, the randomly selected 11 cases with HER-2negative tumors were analyzed for the expression of pAkt and CXCR4. An increased level of pAkt was observed in 9 $(81.8 \%)$ of 11 tumors, and increased expression of CXCR4 was observed in $7(63.6 \%)$ of 11 tumors (Table IV). There was no significant difference in the frequency of positivity of pAkt and CXCR4 between HER-2-positive and HER-2negative tumors, suggesting that the levels of pAkt and CXCR4 were increased by factors that are both dependent and independent of HER-2 in breast tumors with bone metastasis.

Table III. Expression of c-Met, VEGF, MTA-1, Akt, pAkt, and CXCR4 in HER-2-overexpressing breast cancer in patients with bone metastasis.

Factor

\begin{tabular}{|c|c|c|c|c|c|c|c|}
\hline \multirow[b]{2}{*}{ Patient no. } & & & & & & & \\
\hline & HER-2 & c-Met & VEGF & MTA-1 & Aktl/2 & $\mathrm{pAktl} / 2 / 3$ & CXCR4 \\
\hline 1 & $3+$ & - & - & - & - & $3+(\mathrm{N} / \mathrm{C})$ & $1+(\mathrm{C})$ \\
\hline 2 & $3+$ & $1+$ & - & - & - & $2+(C)$ & - \\
\hline 3 & $3+$ & $1+$ focal & - & - & - & $2+(\mathrm{N} / \mathrm{C})$ & $1+(\mathrm{C})$ \\
\hline 4 & $2+$ & $1+$ focal & - & - & - & $1+(\mathrm{C})$ & - \\
\hline 5 & $3+$ & - & - & - & - & $1+\operatorname{DCIS}(\mathrm{C})$ & $1+(\mathrm{C})$ \\
\hline 6 & $3+$ & $+/-$ & $1+$ focal & - & - & $1+(\mathrm{N} / \mathrm{C})$ & $1+(\mathrm{C})$ \\
\hline 7 & $2+$ & - & $1+$ focal & - & - & - & - \\
\hline 8 & $2+$ & $1+$ focal & - & - & - & - & - \\
\hline 9 & $3+$ & $1+$ focal & - & $1+$ focal & - & $2+(\mathrm{N} / \mathrm{C})$ & $1+(\mathrm{C})$ \\
\hline 10 & $2+$ & $+/-$ & $1+$ focal & - & - & $2+(\mathrm{N} / \mathrm{C})$ & - \\
\hline 11 & $3+$ & - & - & $1+$ DCIS & - & $1+(\mathrm{N})$ & $1+(\mathrm{C})$ \\
\hline
\end{tabular}

$\mathrm{N}$, nucleus; C, cytoplasm; DCIS, ductal carcinoma in situ; MTA-1, metastasis-associated protein-1. 
Table IV. Expression of Akt, pAkt, and CXCR4 in HER-2negative breast cancer patients with bone metastasis.

\begin{tabular}{ccccc}
\hline & \multicolumn{4}{c}{ Factor } \\
\cline { 2 - 5 } Patient no. & HER-2 & Aktl/2 & pAktl/2/3 & CXCR4 \\
\hline 1 & 0 & - & $2+(\mathrm{N} / \mathrm{C})$ & - \\
2 & 0 & - & $3+(\mathrm{N} / \mathrm{C})$ & $1+(\mathrm{N})$ \\
3 & 0 & - & $1+(\mathrm{C})$ & - \\
4 & 0 & - & $2+(\mathrm{N} / \mathrm{C})$ & - \\
5 & 0 & - & - & $2+(\mathrm{C})$ \\
6 & 0 & - & $2+(\mathrm{N} / \mathrm{C})$ & $1+(\mathrm{C})$ \\
7 & $1+$ & - & $2+(\mathrm{N} / \mathrm{C})$ & $1+(\mathrm{C})$ \\
8 & $1+$ & - & $2+(\mathrm{N} / \mathrm{C})$ & $1+(\mathrm{C})$ \\
9 & $1+$ & - & $1+(\mathrm{C})$ & - \\
10 & $1+$ & - & $2+(\mathrm{N} / \mathrm{C})$ & $2+(\mathrm{C})$ \\
11 & $1+$ & - & - & $1+(\mathrm{C})$ \\
\hline
\end{tabular}

C, cytoplasm; N, nucleus; DCIS, ductal carcinoma in situ; MTA-1, metastasis-associated protein-1.

\section{Discussion}

In the present study, we explored how the overexpression of HER-2 can affect the formation of bone metastasis in primary breast cancer. The role of several metastasis-related proteins such as c-Met, VEGF, and MTA-1, which are triggered by the overexpression of HER-2, was examined (Fig. 4). Although these proteins were detected, their levels of expression in HER-2 positive tumors were not considered significant. The extranuclear expression of ER and PR was also not observed. The potential relationship between HER-2 and these proteins is rare in clinical cases of breast cancer with bone metastases, even though these connections were observed in HER-2overexpressing breast cancer cells without bone metastasis $(7-9,19)$. In contrast, the increased levels of pAkt and CXCR4 were observed not only in HER-2-positive tumors, but also in HER-2-negative tumors. These findings suggest that the levels of pAkt and CXCR4 were increased by factors that are both dependent and independent of HER-2 in breast cancer with bone metastasis. In a recent study, cytoplasmic expression of CXCR4 in breast cancer was associated with parameters of tumor aggressivity (tumor grade and lymph node status) and had prognostic value with respect to disease-specific survival. CXCR4 positivity in the cytoplasm, but not the nucleus, was associated with HER-2 expression and amplification, as well as with hormone receptor negativity (20). It is conceivable that the increased levels of pAkt and CXCR4 mediated by HER-2 might be involved in the formation of bone metastases. Although factors other than HER-2 for activating pAkt and CXCR4 may be responsible in the formation of bone metastasis, the overexpression of HER-2 may play a critical role in disseminating breast cancer cells from the primary tumor site to the bone marrow.

The interaction between HER-2 and Akt in tumor growth has been suggested in experimental and clinical studies $(21,22)$. Despite the fact that the overexpression of HER-2 activates Akt, Akt can also be activated independently of HER-2. It is reasonable that the increased level of pAkt is not restricted by the induction of HER-2. Assuming that Akt has multifunctional roles in cell survival and tumor proliferation (23), a specific targeted protein and the substrate of Akt were not found in this study. Presumably, certain downstream proteins activated by the HER-2/Akt signaling pathway might be involved in the differentiation of certain breast cancer cells to disseminate to the bone marrow. In fact, activation of the HER-2/Akt signaling pathway is required for activation of several cytokines such as IL-6 (24) and growth factors such as VEGF and bFGF (25) in tumor angiogenesis and metastasis. Furthermore, the HER-2/Akt signaling pathway activates COX-2, which produces prostaglandin E2 (PGE2), which in turn stimulates osteoclast-mediated bone resorption. This effect is abrogated by zoledronic acid because it inhibits the chemotactic effect induced by stromal cell-derived factor 1 (SDF-1), a chemokine greatly involved in breast cancer metastasis to bone (26). The functional significance of the interaction between chemokine receptor CXCR4 and chemokine CXCL12 in promoting metastatic lesions was reported in breast and prostate cancers $(27,28)$. The secretion of CXCL12 in metastatic organs such as lung and bone is a critical factor for recruiting CXCR4expressing tumor cells to metastatic sites. Since there was no significant difference in the increased expression of CXCR4 in HER-2-positive and -negative tumors, it is likely that the expression of CXCR4 is induced by mechanisms that are both HER-2-dependent and -independent in bone metastasis and that HER-2-induced CXCR4 expression is involved in disseminating breast cancer cells to bone marrow.

In a study germane to our interest on micrometastasis of breast cancer cells in the bone marrow, high CXCR4 cytoplasmic expression was found in 7 of 18 patients $(39 \%)$, while 6 of 18 patients (33\%) were found to have cytokeratin (CK) positivity in the bone marrow. The presence of CKpositive cells in the bone marrow was found to be associated with increased expression of CXCR4 alone and with HER-2 expression in primary tumors (29). High CXCR4 expression in breast cancer may be a potential marker for predicting isolated tumor cells in the bone marrow. CXCR4 coexpression together with HER-2 might further predict a particular subset of patients with high $\mathrm{CK}$ positivity in the bone marrow. These findings indicate that the clonal selection for dissemination to the bone marrow might be mediated in part by the increased expression of CXCR and HER-2 during tumor progression.

In another study on the relationship between HER-2 and CXCR4, in which the transactivation of HER-2 by G proteincoupled receptor activation was reported as a ligandindependent mechanism of activating tyrosine kinase receptors, SDF-1 transactivated HER-2 in the MDA-MB-361 and SKBR3 breast cancer cell lines, which both expressed CXCR4 and HER-2 (30). Furthermore, the study indicated that treatment of adenoid cystic carcinomas with CXCL12 resulted in the activation of Akt and ERK1/2 pathways (31), suggesting that Akt plays a crucial role in the activation of the HER-2/CXCR4 signaling pathway for tumor progression and metastasis. In addition, a preclinical study reported that the introduction of HER-2 into MCF-7 breast cancer cells produced osteoblastic bone metastasis in nude mice (32). Thus, the HER-2/CXCR4/ Akt signaling pathway may play a critical role in determining the metastatic destination of breast tumor cells to bone marrow. 
The mechanism by which HER-2/Akt or HER-2/CXCR4 signaling pathways in breast cancer cells produce organspecific metastasis, such as in the bone marrow, remains to be determined. It is unlikely that the interaction of CXCR4 in the primary site and CXCL12 (SDF-1) in the metastatic site is solely responsible for metastatic dissemination to the bone marrow. Rather, additional factors interacting with bone marrow stromal cells in the microenvironment may be involved in the formation of bone metastasis. The mechanisms by which breast cancer cells form metastatic lesions in the bone marrow have been extensively studied. With respect to the interaction of cancer cells with stromal cells in the bone marrow, several growth factors such as TGF- $\beta$, IGF-I (33), VEGF (34), and IL-6 (35) are produced in bone marrow stromal cells, activating the parathyroid hormone-releasing peptide (PTHrP) (27). This results in the activation of osteoclasts or osteoblasts that produce osteolytic or osteoblastic lesions in the bone (36). The activated osteoclasts release growth factors such as IGFs and PDGFs that activate tumor progression, which is termed the 'vicious cycle' between cancer and stromal cells in the bone marrow microenvironment $(36,37)$. These growth factors facilitate the production of metastatic lesions by breast cancer cells in the bone marrow. Further studies will be needed to elucidate the contribution of other factors and their mechanistic connections with the HER-2/CXCR4/Akt signaling pathway in bone metastasis of breast cancer cells.

Finally, the activation of Akt and CXCR4 via factors that are both dependent and independent of HER-2 may play a critical role in disseminating breast cancer cells from the primary tumor to bone marrow. Given that the overexpression of HER-2 is an important factor for activating the HER-2/ CXCR4/Akt signaling pathway, targeting therapy for HER-2 by trastuzumab is beneficial for inhibiting the distant metastasis of breast cancer cells, such as to the bone marrow, as discussed in previous reports.

\section{Acknowledgements}

We would like to thank Mrs. Miyo Oda for her technical assistance with immunohistochemical staining and data assessment in this study.

\section{References}

1. Eccles SA: The role of c-erbB-2/HER2/neu in breast cancer progression and metastasis. J Mammary Gland Biol Neoplasia 6: 393-406, 2001

2. Dowsett M, Cooke T, Ellis I, et al: Assessment of HER2 status in breast cancer: why, when and how? Eur J Cancer 36: 170-176, 2000.

3. Osborne CK, Schiff R, Arpino G, et al: Endocrine responsiveness: understanding how progesterone receptor can be used to select endocrine therapy. Breast 14: 458-465, 2005.

4. Yang W, Klos KS, Zhou X, et al: ErbB2 overexpression in human breast carcinoma is correlated with p21 $1^{\text {Cipl }}$ upregulation and tyrosine- 15 hyperphosphorylation of p34 ${ }^{\mathrm{Cdc} 2}$ : poor responsiveness to chemotherapy with cyclophoshamide methotrexate, and 5-fluorouracil is associated with Erb2 overexpression and with p $21^{\text {Cip } 1}$ overexpression. Cancer 98: 1123-1130, 2003.

5. Schindlbeck C, Janni W, Shabani N, et al: Comparative analysis between the HER 2 status in primary breast cancer tissue and the detection of isolated tumor cells in the bone marrow. Breast Cancer Res Treat 87: 65-74, 2004.
6. Braun S, Schlimok G, Heumos I, et al: ErbB2 overexpression on occult metastatic cells in bone marrow predicts poor clinical outcome of stage I-III breast cancer patients. Cancer Res 61: 1890-1895, 2001.

7. Balana ME, Labriola L, Salatino M, et al: Activation of ErbB-2 via a hierarchical interaction between ErbB-2 and type I insulinlike growth factor receptor in mammary tumor cells. Oncogene 20: 34-47, 2001 .

8. Tolgay Ocal I, Dolled-Filhart M, D'Aquila TG, et al: Tissue microarray-based studies of patients with lymph node-negative breast carcinoma show that met expression is associated with worse outcome but is not correlated with epidermal growth factor family receptors. Cancer 97: 1841-1848, 2003.

9. Laughner E, Taghavi P, Chiles K, et al: HER2 (neu) signaling increases the rate of hypoxia-inducible factor 1alpha (HIF-1 alpha) synthesis: novel mechanism for HIF-1-mediated vascular endothelial growth factor expression. Mol Cell Biol 21: 3995-4004, 2001.

10. Mazumdar A, Wang RA, Mishra SK, et al: Transcriptional repression of oestrogen receptor by metastasis-associated protein 1 corepressor. Nat Cell Biol 3: 30-37, 2001.

11. Muller A, Homey B, Soto $\mathrm{H}$, et al: Involvement of chemokine receptors in breast cancer metastasis. Nature 410: 50-56, 2001

12. Liotta LA: An attractive force in metastasis. Nature 410: 24-25, 2001.

13. Li YM, Pan Y, Wei Y, et al: Upregulation of CXCR4 is essential for HER2-mediated tumor metastasis. Cancer Cell 6: 459-469, 2004.

14. Kishimoto H, Wang Z, Bhat-Nakshatri P, et al: The p160 family coactivators regulate breast cancer cell proliferation and invasion through autocrine/paracrine activity of SDF-1alpha/CXCL12. Carcinogenesis 26: 1706-1715, 2005.

15. Sakamoto G, Inaji H, Akiyama F, et al: General rules for the clinical and pathological recording of breast cancer by the Japanese Breast Cancer Society. Breast Cancer 12: S1-S27, 2005.

16. Hatanaka Y, Hashizume K, Nitta K, et al: Cytometrical image analysis for immunohistochemical hormone receptor status in breast carcinomas. Pathol Int 53: 693-699, 2003.

17. Tsuda H, Tani Y, Hasegawa T, et al: Concordance in judgments among c-erbB-2 (HER2/neu) overexpression detected by two immunohistochemical tests and gene amplification detected by Southern blot hybridization in breast carcinoma. Pathol Int 51: 26-32, 2001.

18. Huang HJ, Neven P, Drijkoningen M, et al: Association between tumour characteristics and HER-2/neu by immunohistochemistry in 1362 women with primary operable breast cancer. J Clin Pathol 58: 611-616, 2005

19. Yang Z, Barnes CJ and Kumar R: Human epidermal growth factor receptor 2 status modulates subcellular localization of and interaction with estrogen receptor alpha in breast cancer cells. Clin Cancer Res 10: 3621-3628, 2004.

20. Salvucci O, Bouchard A, Baccarelli A, et al: The role of CXCR4 receptor expression in breast cancer: a large tissue microarray study. Breast Cancer Res Treat 13: 1-9, 2005

21. Zhou BP, Liao Y, Xia W, et al: Cytoplasmic localization of p21Cip1/WAF1 by Akt-induced phosphorylation in HER-2/neuoverexpressing cells. Nat Cell Biol 3: 245-252, 2001.

22. Bacus SS, Altomare DA, Lyass L, et al: AKT2 is frequently upregulated in HER-2/neu-positive breast cancers and may contribute to tumor aggressiveness by enhancing cell survival. Oncogene 21: 3532-3540, 2002.

23. Nicholson KM and Anderson NG: The protein kinase B/Akt signalling pathway in human malignancy. Cell Signal 14: 381-395, 2002.

24. Qiu Y, Ravi L and Kung HJ: Requirement of ErbB2 for signalling by interleukin-6 in prostate carcinoma cells. Nature 393: 83-85, 1998.

25. Linderholm B, Andersson J, Lindh B, et al: Overexpression of c-erbB-2 is related to a higher expression of vascular endothelial growth factor (VEGF) and constitutes an independent prognostic factor in primary node-positive breast cancer after adjuvant systemic treatment. Eur J Cancer 40: 33-42, 2004.

26. Denoyelle C, Hong L, Vannier JP, et al: New insights into the actions of bisphosphonate zoledronic acid in breast cancer cells by dual RhoA-dependent and -independent effects. Br J Cancer 88: 1631-1640, 2003.

27. Kozlow W and Guise TA: Breast cancer metastasis to bone: mechanisms of osteolysis and implications for therapy. $\mathbf{J}$ Mammary Gland Biol Neoplasia 10: 169-180, 2005. 
28. Taichman RS, Cooper C, Keller ET, et al: Use of the stromal cell-derived factor-1/CXCR 4 pathway in prostate cancer metastasis to bone. Cancer Res 62: 1832-1837, 2002.

29. Cabioglu N, Sahin A, Doucet M, et al: Chemokine receptor CXCR4 expression in breast cancer as a potential predictive marker of isolated tumor cells in bone marrow. Clin Exp Metastasis 22: 39-46, 2005.

30. Darash-Yahana M, Pikarsky E, Abramovitch R, et al: Role of high expression levels of CXCR4 in tumor growth, vascularization, and metastasis. FASEB J 18: 1240-1242, 2004.

31. Muller A, Sonkoly E, Eulert C, et al: Chemokine receptors in head and neck cancer: Association with metastatic spread and regulation during chemotherapy. Int J Cancer, 2005 (Epub ahead of print).

32. Yi B, Williams PJ, Niewolna M, et al: Tumor-derived plateletderived growth factor-BB plays a critical role in osteosclerotic bone metastasis in an animal model of human breast cancer. Cancer Res 62: 917-923, 2002.
33. Kveiborg M, Flyvbjerg A, Eriksen EF, et al: Transforming growth factor-beta1 stimulates the production of insulin-like growth factor-I and insulin-like growth factor-binding protein-3 in human bone marrow stromal osteoblast progenitors. J Endocrinol 169: 549-561, 2001.

34. Fierro FA, Sierralta WD, Epunan MJ, et al: Marrow-derived mesenchymal stem cells: role in epithelial tumor cell determination. Clin Exp Metastasis 21: 313-319, 2004.

35. Roodman DG: Role of stromal-derived cytokines and growth factors in bone metastasis. Cancer 97: 733-738, 2003.

36. Kakonen SM and Mundy GR: Mechanisms of osteolytic bone metastases in breast carcinoma. Cancer 97: 834-839, 2003.

37. Guise TA, Kozlow WM, Heras-Herzig A, et al: Molecular mechanisms of breast cancer metastases to bone. Clin Breast Cancer 5: S46-S53, 2005. 